\title{
Surveillance of Borrelia Miyamotoi-Carrying Ticks and Genomic Analysis of Isolates in Inner Mongolia, China
}

\author{
H Gaowa ( $\square$ melody_gaowa@163.com ) \\ Hetao College \\ W Wulantuya \\ Hetao College \\ Kozue Sato \\ National Institute of Infectious Diseases \\ Dan Liu \\ Hetao College \\ Yunhong Cui \\ Hetao College \\ Xuhong Yin \\ Hetao College \\ Lihua Zhang \\ Hetao College \\ Hong Li \\ Hetao College \\ Tingfu Wang \\ Hetao College \\ Rongxin Liu \\ Hetao College \\ Lijing Wu \\ Hetao College \\ Saixia Lu \\ Hetao College \\ Ting Gao \\ Hetao College \\ Zitong Zhang \\ Hetao College \\ Minzhi Cao \\ Bayan Nur Centers for Disease and Prevention

\section{Guodong Wang} \\ Hulunbuir Centers for Disease Control and Prevention \\ Chunpu Li \\ Hulunbuir Centers for Disease Control and Prevention \\ Dacheng Yan \\ Hulunbuir Centers for Disease Control and Prevention

\section{Norio Ohashi} \\ University of Shizuoka
}

\section{Shuji Ando}

National Institute of Infectious Diseases 


\section{Hiroki Kawabata}

National Institute of Infectious Diseases: Kokuritsu Kansensho Kenkyujo

\section{Research}

Keywords: Ixodes persulcatus, Borrelia miyamotoi, MLST, Inner Mongolia

Posted Date: March 3rd, 2021

DOI: https://doi.org/10.21203/rs.3.rs-273775/v1

License: (c) (i) This work is licensed under a Creative Commons Attribution 4.0 International License. Read Full License

Version of Record: A version of this preprint was published at Parasites \& Vectors on July 17th, 2021. See the published version at https://doi.org/10.1186/s13071-021-04809-z. 


\section{Abstract}

Background: Borrelia miyamotoi is a newly described relapsing fever spirochete transmitted by Ixodid tick species. Little is known about the prevalence of $B$. miyamotoi infections in humans and ticks in Inner Mongolia, China. Therefore, we investigated the prevalence of B. miyamotoi in Ixodes persulcatus, and we aimed to isolate B. miyamotoi from I. persulcatus ticks from four regions of Greater Hinggan, Inner Mongolia, China.

Methods: During May to June of 2016-2019, host-seeking adult ticks of $I$. persulcatus were collected from vegetation. Genomic DNA was prepared from half of each tick body for PCR template, and the remaining half was used to cultivate $B$. miyamotoi in BSK-M medium. We employed quantitative real-time PCR (qPCR) to detect Borrelia DNA in the ticks and to calculate the prevalence of B. miyamotoi and other borreliae infections. For the characterization of isolated B. miyamotoi, we performed draft genome sequencing and multi-loci sequencing analysis (MLSA).

Results: A total of 2,656 I. persulcatus adult ticks were collected. The over-all prevalence of relapsing fever (RF) borreliae in ticks was $5.0 \%(134 / 2,656)$ and that of Lyme disease (LD) borreliae was $43.8 \%(1,164 / 2,656)$. Co-infection by RF and LD borreliae was observed in 63 ticks (2.4\%). Ticks that were positive for RF borreliae on qPCR were subjected to glycerophosphodiester diester phosphodiesterase gene ( $g / p Q)$ PCR amplification and sequencing, through which we identified the RF borreliae specimens as B. miyamotoi. In this study, we successfully isolated the B. miyamotoi strain Hetao- 1 from $I$. persulcatus, and a draft genome sequence was obtained for the isolate. Genomic sequencing revealed the strain Hetao-1 genome to be approximately $906.1 \mathrm{kbp}$ in length (28.9\% average GC content), and MLSA analysis identified the strain as ST633, which was previously reported in Japan and Mongolia.

Conclusion: We detected B. miyamotoi from I. persulcatus ticks collected in Inner Mongolia, and successfully isolated a $B$. miyamotoi strain. To our knowledge, this is the first study to culture a $B$. miyamotoi isolate in China. The data on the prevalence of $B$. miyamotoi and other borreliae in I. persulcatus ticks will be fundamental for future epidemiological studies of $B$. miyamotoi disease in Inner Mongolia.

\section{Background}

Borrelia miyamotoi and the other genetically related relapsing fever (RF) borreliae are transmitted by Ixodid tick species. Ixodes ticks are also vectors of Lyme disease agents $[1,2]$. B. miyamotoi was first discovered from I. persulcatus tick and Apodemus argenteus in Japan [3] and is considered an emerging pathogen of humans [4]. Recently, the spirochete B. miyamotoi was shown to cause infectious disease in humans, designated as $B$. miyamotoi disease (BMD), which has been described in patients in Russia, the United States, several European countries, Japan, and China [4-12]. BMD manifests as a high fever (up to $40^{\circ} \mathrm{C}$ ), fatigue, headaches, myalgia, chills, nausea, and arthralgia, and meningoencephalitis has been reported in immunocompromised patients $[8,13]$. To date, B. miyamotoi has been found in I. scapularis and I. pacificus ticks in North America [14, 15], I. ricinus in Europe [16], and I. persulcatus, I. ovatus, and I. pavlovskyi in Asia [17, 18]. Ixodes ticks are found across the northern hemisphere and are the most common reservoir and vector of many pathogenic agents, including viruses, bacteria, and protozoa of medical importance.

In China, cases of Lyme disease (LD) have been reported in Greater Hinggan and Lesser Hinggan in the north east, where the principal LD vector, I. persulcatus, is abundant [19]. I. persulcatus is also a very common vector of B. miyamotoi. Human infection with B. miyamotoi was also reported in northeastern China in 2018 and has been detected in I. persulcatus ticks [12]. However, there has been a lack of wide-area surveys of $B$. miyamotoi infection in tick populations, including I. persulcatus and other Ixodes species. Not only do the epidemiological data in China remain unclear but also the genetic characteristics of $B$. miyamotoi because of the difficulty with cultivating the bacteria. This basic information on the prevalence of $B$. miyamotoi infection in ticks and the genetic characterization of the pathogen are urgently required for risk assessments of BMD in northeastern China. 
The Greater Hinggan region in northeastern China offers favorable environmental conditions for the survival and proliferation of I. persulcatus. In this area, tick ectoparasitic are highly prevalent on humans, and human ixodid tick-borne infections, including those caused by LD borreliae and tick-borne encephalitis virus (genus Flavivirus), are endemic and transmitted by the same tick species [20]. However, some febrile patients have presented with a recent tick bite that could not have been infected with the tick-borne pathogen diagnosed. In this study, large-scale surveillance for B. miyamotoi was conducted in Greater Hinggan to estimate the infection rate of host-seeking adult Ixodes ticks. The tick-derived isolates of $B$. miyamotoi discovered in this study were subjected to molecular analyzes to characterize their genetic profile. The resultant field and laboratory data will serve as a baseline for research aiming to understand the epidemiology of B. miyamotoi in Inner Mongolia, China.

\section{Methods}

\section{Study area}

The tick samples in this study were collected in different forested areas throughout Greater Hinggan in Hulun Buir City of Inner Mongolia, northeastern China (Fig. 1). The Greater Hinggan forest region of Inner Mongolia is in the northernmost area of the Greater Hinggan Mountains, accounting for $46 \%$ of the total area, with geographical coordinates ranging from $119^{\circ} 36^{\prime} 30^{\prime \prime}$ to $125^{\circ} 24^{\prime} 00^{\prime \prime} \mathrm{E}$ and $47^{\circ} 03^{\prime} 40^{\prime \prime}$ to $53^{\circ} 20^{\prime} 00^{\prime \prime} \mathrm{N}$. The main habitat is primeval forest at an altitude of $250-1,745$ meters, an average annual temperature of $-3.5^{\circ} \mathrm{C}$, and an annual precipitation of $300-450 \mathrm{~mm}$. In these areas, no specific permissions were required for the collection of ticks, and this study did not involve endangered or protected species.

\section{Tick collection, DNA extraction, and borrelial cultivation}

During 2016-2019, from May to June each year, host-seeking adult ticks were collected by flagging from vegetation. The collected tick samples were placed in a collection tube, which were classified and numbered according to the sampling time and place. I. persulcatus ticks were identified on the basis of the morphological characteristics. Ticks were washed with $0.1 \%$ sodium hypochlorite and $75 \%$ ethanol containing povidone iodine for $5 \mathrm{~min}$, washed again with $3 \%$ hydrogen peroxide for 5 min, and then rinsed with sterile water. Genomic DNA PCR template was prepared from half of each tick body according to Yamazaki-Matsune et al. [21]. The remaining half was used to cultivate B. miyamotoi in modified Barbour-Stoenner-Kelly medium (BSK-M: using minimal essential medium alpha [Bio West, Germany] as a substitute for CMRL-1066) under microaerophilic conditions [17, 22]. The tick samples that were positive for RF borreliae and negative for LD borreliae on qPCR were cultivated at $30^{\circ} \mathrm{C}$ for 4 weeks, and the growth of spirochetes was examined by dark-field microscopy every 2 weeks.

\section{Detection of borrelial DNA from ticks}

Tick lysates were subjected to qPCR assay to detect borrelial infection. The assay was designed to specifically detect RF borreliae, including B. miyamotoi, and LD-related spirochetes. The system was originally established by Barbour et al. [23], and the borrelial DNA in the tick lysates was detected by multiplex qPCR targeting the 16S rRNA gene (16S rDNA). To allow detection of most Borrelia spp., common primers were designed to conserved sequences, and specific DNA probes conjugated to non-fluorescent quencher (NFQ) and minor groove-binder architectural protein (MGB) were designed. The two probes were labeled with either the fluorescence reporter group FAM or VIC, and the multi-qPCR reaction system was able to simultaneously detect RF and LD borreliae. The forward and reverse primers were 5'-GCTGTAAACGATGCACACTTGGT-3' and 5'GGCGGCACACTTAACACGTTAG-3', respectively. The corresponding dye-labeled probes, FAM-TTCGGTACTAACTTTTAGTTAANFQ-MGB and VIC-CGGTACTAACCTTTCGATTA-NFQ-MGB, were purchased from Applied Biosystems (Foster City, CA). The qPCR was performed using Premix Ex Taq (Probe qPCR, Takara Bio Inc., Shiga, Japan) according to the manufacturer's instructions and run on a Bio-Rad CFX96 system with 42 PCR cycles.

\section{Conventional PCR and phylogeny reconstruction using glpQ sequences}

To confirm the qPCR results, we performed conventional PCR on the tick-derived isolates. Ticks that were found to be RF-DNApositive by qPCR were subjected to glycerophosphodiester diester phosphodiesterase gene $(g / p Q)$ analysis with PCR-based DNA sequencing [24] using primers purchased from Nanjing GenScript Biological Technology Company: forward primer ( $g / p Q-$ 
F), 5'-CATACGCTTATGCYTTRGGMGCTGA-3', and reverse primer ( $g / p Q-R)$, 5'-GCAACCTCTGYCATACCTTCTTSTG-3'. The amplicon was approximately $610 \mathrm{bp}$ in length. The reaction conditions of the first PCR were $3 \mathrm{~min} 94^{\circ} \mathrm{C}$, then 30 cycles of $30 \mathrm{~s}$ at $94^{\circ} \mathrm{C}, 30 \mathrm{~s}$ annealing at $53^{\circ} \mathrm{C}, 30 \mathrm{~s}$ at $72^{\circ} \mathrm{C}$, and finishing with $5 \mathrm{~min}$ at $72^{\circ} \mathrm{C}$. In the second $\mathrm{PCR}$, the annealing temperature was changed to $55^{\circ} \mathrm{C}$. We employed the Blend Tag-Plus enzyme (TOYOBO, Osaka, Japan) in the PCR reactions, and the operation was conducted in accordance with the instructions. A negative control was used in each PCR amplification. After amplification, $5 \mu \mathrm{L}$ of PCR product was separated on 1\% agarose gel electrophoresis and visualized by ethidium bromide staining. PCR products containing the target fragment were sent to the Nanjing GenScript Biological Technology Company for bidirectional sequencing. We conducted phylogenetic analyses based on the nucleotide sequences of $g / p Q$ ( $555 \mathrm{bp})$ using the maximum likelihood method [25] in MEGA 6.0 [26]. Homologous sequences were searched for with BLAST in NCBI and downloaded. ClustalW software was used for sequence alignment analysis, and its reliability was tested with bootstrap analysis with 1000 replicates.

\section{De novo sequencing and multi-loci sequencing analysis based on draft genome data of cultured isolate}

Genomic DNA was extracted from the B. miyamotoi strain Hetao-1 according to Lim et al. [27]. For genomic library construction, $1 \mu \mathrm{g}$ of DNA was used for DNA sample preparation, and sequencing libraries were generated using the Next Ultra DNA Library Prep Kit for Illumina (NEB, USA) following the manufacturer's instructions. Briefly, the DNA sample was fragmented by sonication to approximately $350 \mathrm{bp}$, then DNA fragments were end-polished, A-tailed, and ligated with the full-length adaptor for Illumina sequencing with further PCR amplification. The PCR products were purified (AMPure XP system), and libraries were analyzed for size distribution on the Agilent 2100 Bioanalyzer and quantified using real-time PCR. The whole genome of $B$. miyamotoi strain Hetao-1 was sequenced using Illumina NovaSeq PE150. For genome assembly, the raw data were independently assembled using SOAP denovo v.1.0 [28], SPAdes [29], and ABySS v.2.0 [30]. The assembly results for the three software packages were integrated with CISA software [31], and the assembly result with the fewest scaffolds was selected. De novo sequencing and assembling were performed at the Beijing Novogene Bioinformatics Technology.

Multi-loci sequencing analysis (MLSA) was performed using the MLSA dataset proposed by Margos et al. extracted from the draft genome sequence of strain Hetao-1. The loci of eight genes ( $c / p A, c / p X, n i f S, p e p X, p y r G, r e c G, r p / B$, and $u v r A)$ were concatenated and used in this analysis according to Margos et al. [32].

\section{Results}

\section{Ticks infected with borreliae in Inner Mongolia}

A total of 2,656 adult I. persulcatus ticks were collected from the Daxingan mountains in Hulun Buir City of Inner Mongolia, China (Fig. 1). All the collected ticks were screened for borreliae DNA by qPCR targeting of the 16S rDNA. As shown in Table 1, ticks harboring B. miyamotoi were found from four districts: Genhe, Yakeshi, Arong Banner, and Arxan. The overall prevalence of RF borreliae, including B. miyamotoi, in ticks of Hulun Buir was 5.0\% (134/2656). In more detail, the percentages of ticks positive for RF borreliae were 8.6\% in Genhe, 5.1\% in Yakeshi, 2.6\% in Arong Banner, and $14.0 \%$ in Arxan (Table 1). The overall prevalence of LD borreliae was 43.8\% (1164/2656), and the percentages of ticks positive for LD borreliae were $59.5 \%$ in Genhe, 45.0\% in Yakeshi, 31.3\% in Arong Banner, and 55.8\% in Arxan (Table 1). Co-infection by RF and LB borreliae was observed in 46 ticks $(1.7 \%)$ in Hulun Buir.

\section{Identification of B. miyamotoi in ticks}

To identify the RF borrelia in ticks from Hulun Buir, we performed sequence analysis followed by glpQ qPCR of RF-borreliapositive samples (134 samples). Of these 134 tick samples, we successfully sequenced partial glpQ from 105, and these sequences were $100 \%$ identical to each another and to that of the B. miyamotoi strain FR64b (accession number: CP004217)

(Fig. 2). Nucleotide sequences of the representative B. miyamotoi isolate from Hulun Buir were deposited in the DDBJ/GenBank DNA database with the following accession numbers: LC570864-LC570882. In 29 of the tick specimens, weak or no amplification of $g l p Q$ was seen. The reason for this is unknown; however, the negative control qPCR showed no amplification. 
Thus, we believe it is possible that this absence of a signal in qPCR may be due to the cross-contamination of $B$. miyamotoi in this study.

\section{Genetic characterization of B. miyamotoi DNA from cultured isolates and ticks using glpQ genes}

We successfully cultured one B. miyamotoi isolate from I. persulcatus tick using BSK-M medium. This isolate was used in the initial qPCR confirmation of the pathogen and for analyzing the $g / p Q$ sequences. Based on the amplified region of the $g / p Q$ gene, the Hetao-1 isolated in this study (accession number: LC557152) clustered together with Siberian B. miyamotoi strains isolated in Japan and Russia (Fig. 2).

\section{MLSA by draft genome sequence}

A draft genomic sequence of the B. miyamotoi isolated from ticks sampled in Inner Mongolia was obtained to characterize the Hetao-1 strain. The chromosome of the strain was estimated to be approximately $906.1 \mathrm{~kb}$ in length with a GC content of 28.9\%. The chromosome sequence showed 46 single nucleotide polymorphisms (SNPs) without Ins/Del compared with the $B$. miyamotoi strain Izh-4 (accession number: CP024390) [33]. Using the genome assembly data, MLST was carried out using eight genes ( $c / p A, c / p X$, nifS, pepX, pyrG, recG, rp/B, and uvrA) isolated from the draft genome sequence. Analysis of the eight concatenated housekeeping gene sequences (4,776 nucleotides) identified the Chinese Hetao- 1 isolate from I. persulcatus as ST633 and to be identical to B. miyamotoi Japanese isolate HT31 (Japan) and M12C4 (Mongolia) (Fig. 3).

\section{DNA Accession number}

Accession numbers obtained in this study is as follows; $B$. miyamotoi strain Hetao-1 CTP synthase gene (pyrG), DNA helicase gene (recG), ATP-dependent endopeptidase clp ATP-binding subunit gene ( $c l p X)$, Aspartyl aminopeptidase gene (pepX), Excinuclease ABC subunit A gene (uvrA), Cysteine desulfurase gene (nifS), ATP-dependent Clp protease subunit A gene ( $c / p A)$, LSU ribosomal protein L2P gene ( $r p / B)$, 16SrRNA, and flagellin gene (flaB) are LC557142, LC557143, LC557144, LC557145, LC557146, LC557147, LC557148, LC557149, LC557150, and LC557151, respectively.

\section{Discussion}

The $B$. miyamotoi bacterium is a newly described emerging pathogen. Before this study, no isolates of this bacterium from China had been cultured, and there was little information on $B$. miyamotoi infections in human and ticks [12, 34, 35]. In this study, we detected B. miyamotoi in I. persulcatus ticks and successfully isolated a B. miyamotoi strain from I. persulcatus collected in Greater Hinggan, Inner Mongolia, China. Our findings demonstrated that B. miyamotoi infection of I. persulcatus is widespread across the regions examined. Similar to in Russia and Japan, I. persulcatus ticks in Greater Hinggan, China, are mainly abundant in forested regions. To date, there have been no reports on the prevalence of $B$. miyamotoi infections in humans and ticks in Greater Hinggan; however, human tick bites and tick-borne LD or TBE are known to occur frequently in this region. We conducted large-scale tick surveillance for $B$. miyamotoi in Greater Hinggan, as human cases of $B$. miyamotoi infection were confirmed in Jilin and Heilongjiang, China, in 2018, and B. miyamotoi has been found previously in I. persulcatus ticks [12]. From our research, the frequency of B. miyamotoi infections in I. persulcatus was shown to be approximately $5 \%$, which is similar to the prevalence shown by the most recent study in China (approximately $3 \%$ in I. persulcatus) [12, 35]. Most previous reports suggest that Ixodes ticks are transmission vectors of $B$. miyamotoi in North America, Europe, and other Asian countries. Our results support the hypothesis that I. persulcatus is an important $B$. miyamotoi transmission vector in Inner Mongolia, China.

Before this study, other tick species (Haemaphysalis and Dermacentorticks) were found to carry B. miyamotoi in China [12, 34, 35]. The potential of Haemaphysalis and Dermacentor ticks to act as vectors of B. miyamotoi remains unclear; however, Haemaphysalis is suggested to be a vector of Borrelia species related to B. thaileri in Japan [36, 37]. The Borrelia species (i.e., Borrelia sp. HL) was classified as a hard-tick-borne RF borreliae; however, it is clearly distinguishable from B. miyamotoi. Thus, further study may be required on the vectorial capacity of these tick species to clarify the risk of BMD in China. 
The data collated in this study provide information on the risk of B. miyamotoi infection (Table 1). Additionally, we detected LD borreliae from $43.8 \%$ of $I$. persulcatus ticks, which are thought to be the vectors of $B$. miyamotoi and LD borreliae in Inner Mongolia. Although the prevalence of $B$. miyamotoi is lower than that of LD borreliae in Greater Hinggan, B. miyamotoi, as a cause of fever and various other symptoms, is also a risk to public health.

Using MLSA, we revealed that B. miyamotoi ST633, which was previously found in Mongolia and Japan [38], is distributed in several regions of Inner Mongolia. Furthermore, the draft genome sequence revealed the Inner Mongolia isolate has only 46 chromosomal SNPs compared with the $B$. miyamotoi strain Izh-4, although no geographical relationship was observed between these strains. The reason for the similarity is unknown; however, clonal expansion of $B$. miyamotoi may have occurred with the migration of vectors/reservoirs throughout Asian countries, including Russia. To resolve this question, further epidemiological studies of $B$. miyamotoi infection are required.

\section{Conclusion}

In this study, we detected B. miyamotoi in I. persulcatus ticks from Inner Mongolia, China, and successfully isolated a strain of B. miyamotoi. To our knowledge, this is the first report of the isolation of $B$. miyamotoi from China. Further epidemiological studies investigating the prevalence of $B$. miyamotoi and other borreliae in I. persulcatus ticks will provide new insights into the epidemiological aspects of $B$. miyamotoi infection in Inner Mongolia, China.

\section{Declarations}

- Ethics approval and consent to participate

Not applicable

- Consent for publication

Not applicable

- Availability of data and materials

The datasets used and/or analyzed in the current study are available from Gaowa on reasonable request.

- Competing interests

The authors declare that they have no competing interests.

- Funding

The research was supported by the following grants: National Natural Science Foundation of China (nos. 31660032 and 31660044), Inner Mongolia Science and Technology Talent Project for Youth (NJYT-18-A19), Science and Technology Program of Inner Mongolia; Bayan Nur Doctoral Scientific Research Station (no. BKZ2016), The Grassland Elite Program of Inner Mongolia, The Hetao Talent Program of Bayan Nur (to Gaowa), AMED under Grant Numbers JP20wm0225016, JP20fk0108068 and 21fk0108614.

- Authors' contributions

Gaowa designed the study and wrote the manuscript. All authors contributed to tick collection. All PCR analyses were performed by Gaowa. K.S. and H.K. supported borrelial culture in Inner Mongolia. H.K. provided helpful advice and discussion. All the authors agreed to the final version of the manuscript.

Acknowledgments

Page $7 / 12$ 
We thank Suzanne Leech, Ph.D., from Liwen Bianji, Edanz Editing China (www.liwenbianji.cn/ac), for editing the English text of a draft of this manuscript.

\section{References}

1. Mather TN, Mather ME. Intrinsic Competence of Three Ixodid Ticks (Acari) as Vectors of the Lyme Disease Spirochete. J Med Entomol. 1990;4:646-50.

2. Niu Q, Guan G, Yang J, Fu Y. Detection and differentiation of Borrelia burgdorferi sensu lato in ticks collected from sheep and cattle in China. BMC Vet Res. 2011;7:56.

3. Fukunaga M, Takahashi Y, Tsuruta Y, Matsushita O, Ralph D, McClelland M, et al. Genetic and phenotypic analysis of Borrelia miyamotoi sp. nov., isolated from the ixodid tick Ixodes persulcatus, the vector for Lyme disease in Japan. Int J Syst Bacteriol. 1995;45(4):804-10.

4. Platonov AE, Karan LS, Kolyasnikova NM, Makhneva NA, Toporkova MG, Maleev VV, et al. Humans Infected with Relapsing Fever Spirochete Borrelia miyamotoi, Russia. Emerg Infect Dis. 2011;17:1816-23.

5. Krause PJ, Fish D, Narasimhan S, Barbour GA. Borrelia miyamotoi infection in nature and in humans. Clin Microbiol Infect. 2015;21:631-9.

6. Krause PJ, Narasimhan S, Wormser GP, Rollend L, Fikrig E, Lepore T, et al. Human Borrelia miyamotoi infection in the United States. N Engl J Med. 2013;368(3):291-3.

7. Hovius JW, de Wever B, Sohne M, Brouwer MC, Coumou J, Wagemakers A, et al. A case of meningoencephalitis by the relapsing fever spirochaete Borrelia miyamotoi in Europe. Lancet. 2013;382(9892):658.

8. Boden K, Lobenstein S, Hermann B, Margos G, Fingerle V. Borrelia miyamotoi-Associated Neuroborreliosis in Immunocompromised Person. Emerg Infect Dis. 2016;22(9):1617-20.

9. Henningsson AJ, Asgeirsson H, Hammas B, Karlsson E, Parke Å, Hoornstra D, et al. Two Cases of Borrelia miyamotoi Meningitis, Sweden, 2018. Emerg Infect Dis. 2019;25(10):1965-8.

10. Tobudic S, Burgmann H, Stanek G, Winkler S, Schötta AM, Obermüller M, et al. Human Borrelia miyamotoi Infection, Austria. Emerg Infect Dis. 2020;26(9):2201-4.

11. Sato K, Takano A, Konnai S, Nakao M, Ito T, Koyama K, et al. Human infections with Borrelia miyamotoi, Japan. Emerg Infect Dis. 2014;20(8):1391-3.

12. Jiang BG, Jia N, Jiang JF, Zheng YC, Chu YL, Jiang RR, et al. Borrelia miyamotoi Infections in Humans and Ticks, Northeastern China. Emerg Infect Dis. 2018;24(2):236-41.

13. Gugliotta JL, Goethert HK, Berardi VP, Telford SR 3. rd. Meningoencephalitis from Borrelia miyamotoi in an immunocompromised patient. N Engl J Med. 2013;368(3):240-5.

14. Mun J, Eisen RJ, Eisen L, Lane RS. Detection of a Borrelia miyamotoi sensu lato relapsing-fever group spirochete from Ixodes pacificus in California. J Med Entomol. 2006;43(1):120-3.

15. Graham CB, Pilgard MA, Maes SE, Hojgaard A, Eisen RJ. Paired real-time PCR assays for detection of Borrelia miyamotoi in North American Ixodes scapularis and Ixodes pacificus (Acari: Ixodidae). Ticks and Tick-borne Diseases; 2016;7:12301235.

16. Geller J, Nazarova L, Katargina O, Järvekülg L, Fomenko N, Golovljova I. Detection and genetic characterization of relapsing fever spirochete Borrelia miyamotoi in Estonian ticks. PLoS One. 2012;7(12):e51914.

17. Takano A, Toyomane K, Konnai S, Ohashi K, Nakao M, Ito T, et al. Tick surveillance for relapsing fever spirochete Borrelia miyamotoi in Hokkaido, Japan. PLoS One. 2014;9(8):e104532.

18. Iwabu-Itoh Y, Bazartseren B, Naranbaatar O, Yondonjamts E, Furuno K, Lee K, et al. Tick surveillance for Borrelia miyamotoi and phylogenetic analysis of isolates in Mongolia and Japan. Ticks Tick Borne Dis. 2017;8:850-57.

19. Li ZY, Liu HH, Liu Q, Ma HY, Wei F. Molecular detection of Hepatozoon sp. in ticks from northeastern China. Chinese Journal of Veterinary Science. 2018;38:1720-4. 
20. Chu CY, Jiang BG, He J, Gao Y, Zhang PH, Wu XM, et al. Genetic Diversity of Borrelia burgdorferi Sensu Lato Isolates from Northeastern China. Vector Borne Zoonotic Dis. 2011;11(7):877-82.

21. Yamazaki-Matsune W, Taguchi M, Seto K, Kawahara R, Kawatsu K, Kumeda Y, et al. Development of a multiplex PCR assay for identification of Campylobacter coli, Campylobacter fetus, Campylobacter hyointestinalis subsp. hyointestinalis, Campylobacter jejuni, Campylobacter lari and Campylobacter upsaliensis. J Med Microbiol. 2007;56:1467-73.

22. Barbour AG. Isolation and cultivation of Lyme disease spirochetes. Yale J Biol Med. 1984;57:521-5.

23. Barbour AG, Bunikis J, Travinsky B, Hoen AG, Diuk-Wasser MA, Fish D, et al. Niche partitioning of Borrelia burgdorferi and Borrelia miyamotoi in the same tick vector and mammalian reservoir species. Am J Trop Med Hyg. 2009;81:1120-31.

24. Takano A, Fujita H, Kadosaka T, Konnai S, Tajima T, Watanabe H, et al. Characterization of reptile-associated Borrelia sp. in the vector tick, Amblyomma geoemydae, and its association with Lyme disease and relapsing fever Borrelia spp. Environ Microbiol Rep. 2011;3:632-7.

25. Kimura M. A simple method for estimating evolutionary rate of base substitutions through comparative studies of nucleotide sequences. J Mol Evol. 1980;16:111-20.

26. Tamura K, Stecher G, Peterson D, Filipski A, Kumar S. MEGA6: Molecular Evolutionary Genetics Analysis version 6.0. Mol Biol Evol. 2013;30:2725-9.

27. Lim HJ, Lee EH, Yoon Y, Cha B, Son A. Portable lysis apparatus for rapid single-step DNA extraction of Bacillus subtilis. J Appl Microbiol. 2016;120:379-87.

28. Li R, Zhu H, Ruan J, Qian W, Fang X, Shi Z, et al. De novo assembly of human genomes with massively parallel short read sequencing. Genome Res. 2010;20:265-72.

29. Bankevich A, Nurk S, Antipov D, Gurevich AA, Dvorkin M, Kulikov AS, et al. SPAdes: a new genome assembly algorithm and its applications to single-cell sequencing. J Comput Biol. 2012;19:455-77.

30. Simpson JT, Wong K, Jackman SD, Schein JE, Jones SJ, Birol I. ABySS: a parallel assembler for short read sequence data. Genome Res. 2009;19(6):1117-23.

31. Lin SH, Liao YC. CISA: Contig Integrator for Sequence Assembly of Bacterial Genomes. PLoS ONE. 2013;8(3):e60843.

32. Margos G, Gatewood AG, Aanensen DM, Hanincová K, Terekhova D, Vollmer SA, et al. MLST of housekeeping genes captures geographic population structure and suggests a European origin of Borrelia burgdorferi. Proc Natl AcadSci USA. 2008;105:8730-5.

33. Kuleshov KV, Margos G, Fingerle V, Koetsveld J, Goptar IA, Markelov ML, et al. Whole genome sequencing of Borrelia miyamotoi isolate Izh-4: reference for a complex bacterial genome. BMC Genomics. 2020;21:16.

34. Yang Y, Yang Z, Kelly P, Li J, Ren Y, Wang C. Borrelia miyamotoi sensu lato in Pere David Deer and Haemaphysalis longicornis Ticks. Emerg Infect Dis. 2018;24:928-31.

35. Gao Y, Lv XL, Han SZ, Wang W, Liu Q, Song M. First detection of Borrelia miyamotoi infections in ticks and humans from the northeast of Inner Mongolia, China. Acta Trop. 2021;217:105857.

36. Lee K, Takano A, Taylor K, Sashika M, Shimozuru M, Konnai S, et al. A relapsing fever group Borrelia sp. similar to Borrelia lonestari found among wild sika deer (Cervus nippon yesoensis) and Haemaphysalis spp. ticks in Hokkaido, Japan. Ticks Tick Borne Dis. 2014;5:841-7.

37. Kumagai Y, Sato K, Taylor KR, Zamoto-Niikura A, Imaoka K, Morikawa S, et al. A relapsing fever group Borrelia sp. is widely distributed among wild deer in Japan. Ticks Tick Borne Dis. 2018;9:465-70.

38. Iwabu-Itoh Y, Bazartseren B, Naranbaatar O, Yondonjamts E, Furuno K, Lee K, et al. Tick surveillance for Borrelia miyamotoi and phylogenetic analysis of isolates in Mongolia and Japan. Ticks Tick Borne Dis. 2017;8:850-7.

\section{Tables}


Table 1. Prevalence of Borreliae in Ixodes persulcatus tick

\begin{tabular}{|c|c|c|c|c|c|c|c|c|c|c|c|c|}
\hline \multirow[t]{2}{*}{$\begin{array}{l}\text { Location } \\
\text { in Hulun } \\
\text { Buir }\end{array}$} & \multicolumn{3}{|c|}{ No. of ticks } & \multicolumn{3}{|c|}{$\begin{array}{l}\text { RF borreliae (including B. } \\
\text { miyamotoi) positive No. } \\
(\%)\end{array}$} & \multicolumn{3}{|c|}{$\begin{array}{l}\text { LD borreliae positive No. } \\
(\%)\end{array}$} & \multicolumn{3}{|c|}{ Co-infection No. (\%) } \\
\hline & Male & Female & Total & Male & Female & Total & Male & Female & Total & Male & Female & Total \\
\hline Genhe & 56 & 60 & 116 & $\begin{array}{l}6 \\
(10.7)\end{array}$ & $4(6.7)$ & $\begin{array}{l}10 \\
(8.6)\end{array}$ & $\begin{array}{l}36 \\
(64.3)\end{array}$ & $\begin{array}{l}33 \\
(55.0)\end{array}$ & $\begin{array}{l}69 \\
(59.5)\end{array}$ & $\begin{array}{l}3 \\
(5.4)\end{array}$ & 0 & $\begin{array}{l}3 \\
(2.6)\end{array}$ \\
\hline Yakeshi & 1023 & 1090 & 2113 & $\begin{array}{l}58 \\
(5.7)\end{array}$ & $\begin{array}{l}50 \\
(4.6)\end{array}$ & $\begin{array}{l}108 \\
(5.1)\end{array}$ & $\begin{array}{l}439 \\
(42.9)\end{array}$ & $\begin{array}{l}512 \\
(47.0)\end{array}$ & $\begin{array}{l}951 \\
(45.0)\end{array}$ & $\begin{array}{l}11 \\
(1.1)\end{array}$ & $\begin{array}{l}43 \\
(3.9)\end{array}$ & $\begin{array}{l}54 \\
(1.6)\end{array}$ \\
\hline $\begin{array}{l}\text { Arong } \\
\text { Banner }\end{array}$ & 217 & 167 & 384 & $\begin{array}{l}4 \\
(1.8)\end{array}$ & $6(3.6)$ & $\begin{array}{l}10 \\
(2.6)\end{array}$ & $\begin{array}{l}78 \\
(35.9)\end{array}$ & $\begin{array}{l}42 \\
(25.1)\end{array}$ & $\begin{array}{l}120 \\
(31.3)\end{array}$ & $\begin{array}{l}1 \\
(0.5)\end{array}$ & $4(2.4)$ & $\begin{array}{l}5 \\
(2.1)\end{array}$ \\
\hline Arxan & 22 & 21 & 43 & $\begin{array}{l}4 \\
(18.2)\end{array}$ & $2(9.5)$ & $\begin{array}{l}6 \\
(14.0)\end{array}$ & $\begin{array}{l}9 \\
(40.9)\end{array}$ & $\begin{array}{l}15 \\
(71.4)\end{array}$ & $\begin{array}{l}24 \\
(55.8)\end{array}$ & $\begin{array}{l}1 \\
(4.5)\end{array}$ & 0 & $\begin{array}{l}1 \\
(2.3)\end{array}$ \\
\hline Total & 1315 & 1341 & 2656 & $\begin{array}{l}72 \\
(5.5)\end{array}$ & $62(4.6)$ & $\begin{array}{l}134 \\
(5.0)\end{array}$ & $\begin{array}{l}562 \\
(42.6)\end{array}$ & $\begin{array}{l}602 \\
(45.0)\end{array}$ & $\begin{array}{l}1164 \\
(43.8)\end{array}$ & $\begin{array}{l}16 \\
(1.2)\end{array}$ & $\begin{array}{l}47 \\
(3.5)\end{array}$ & $\begin{array}{l}63 \\
(2.4)\end{array}$ \\
\hline
\end{tabular}

\section{Figures}

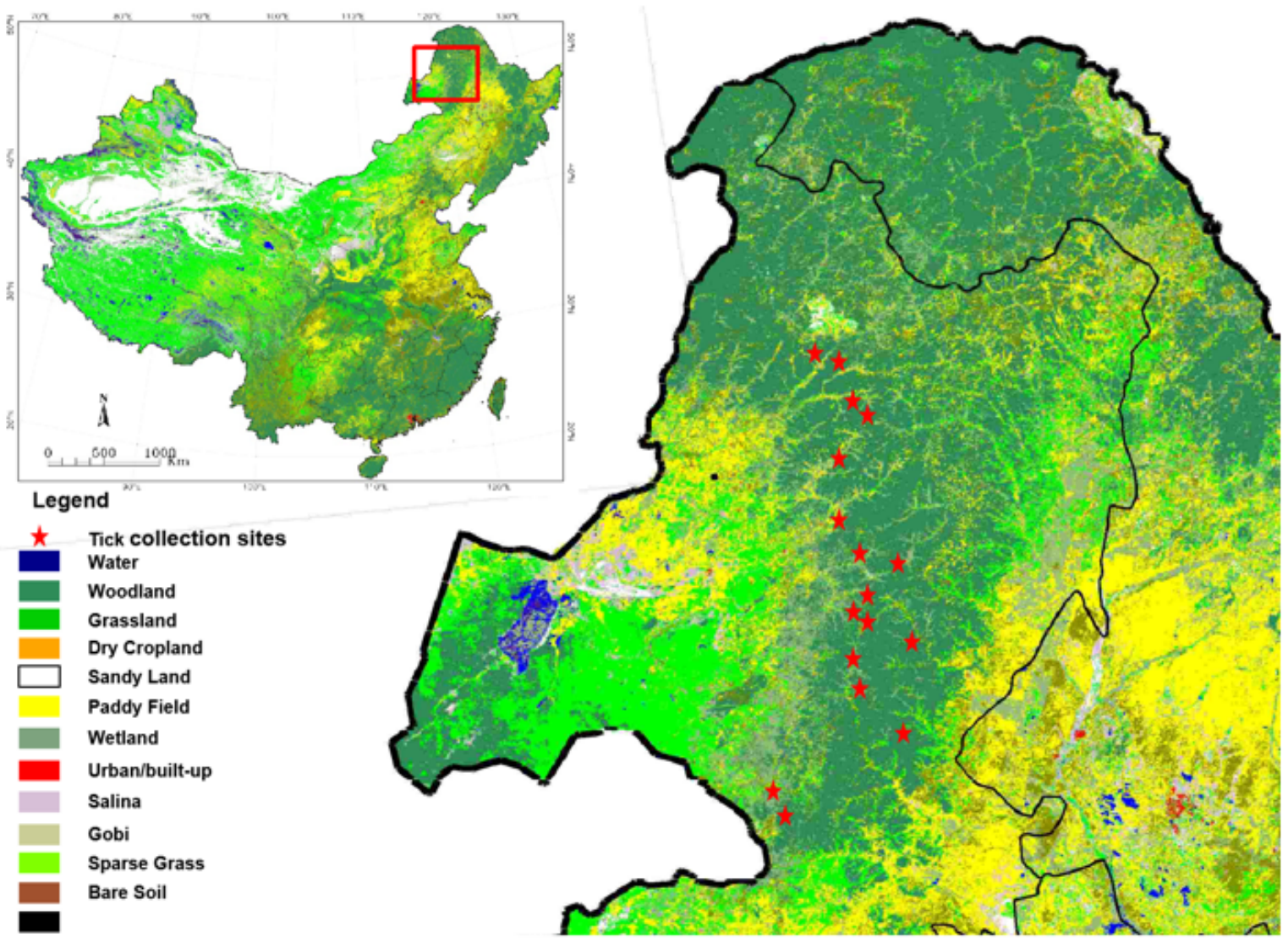

Figure 1

Tick collection areas in this study. Ticks were collected from the areas shown by red stars. Note: The designations employed and the presentation of the material on this map do not imply the expression of any opinion whatsoever on the part of 
Research Square concerning the legal status of any country, territory, city or area or of its authorities, or concerning the delimitation of its frontiers or boundaries. This map has been provided by the authors.

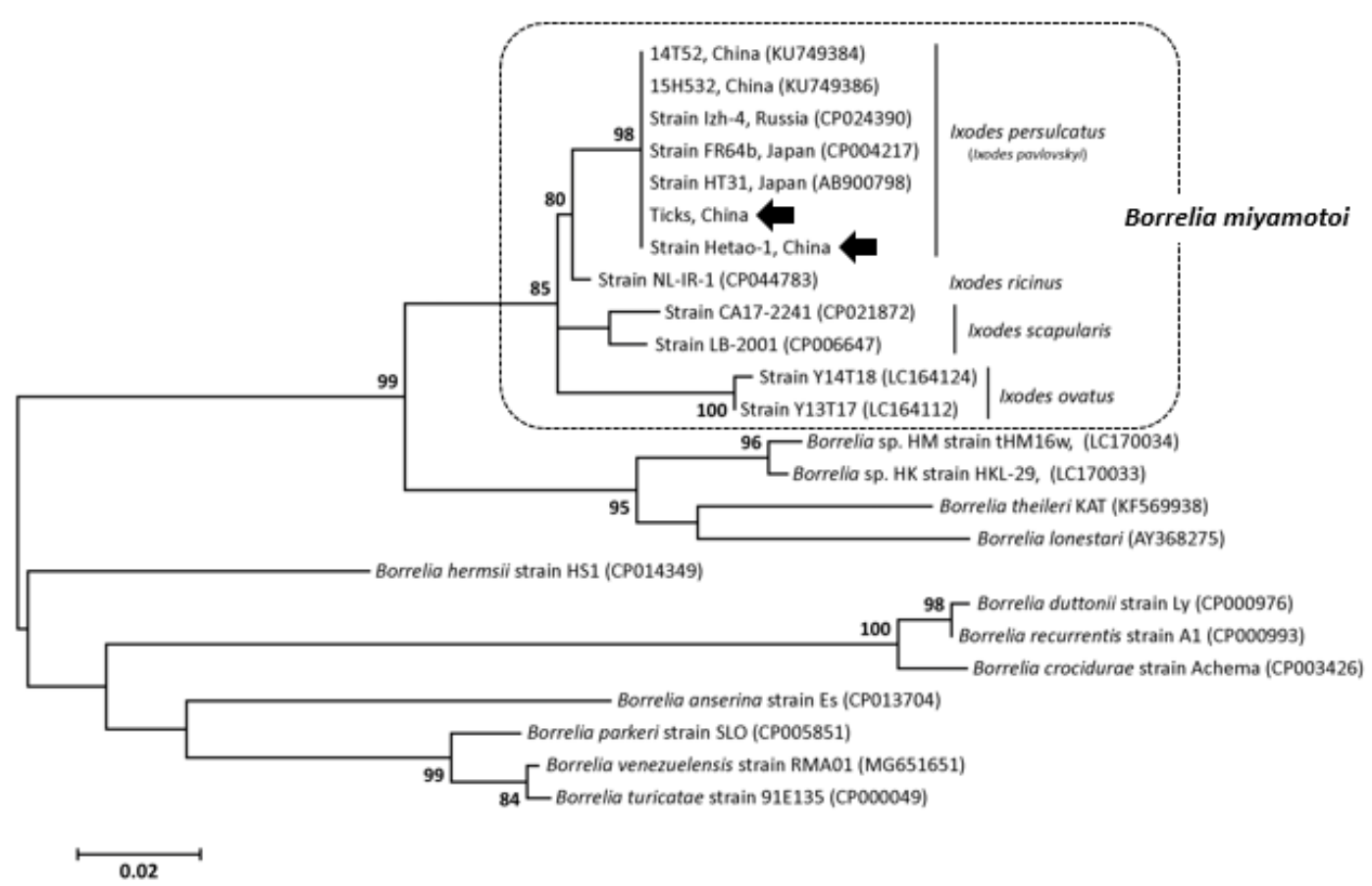

Figure 2

Phylogenetic analysis of RF borreliae based on glpQ. The tree was constructed based on glpQ sequences by the Maximun Likelihood method based on the Kimura 2-parameter model with 1,000 bootstraps resamplings. The bar indicates the percentage of sequence divergence. Borrelia miyamotoi found in this study, was pointed by black arrows. Putative tick vector of each B. miyamotoi group was listed after each lineages. The number in parentheses indicates Accession Number in GenBank. Accession number of B. miyamotoi "Ticks, China" was from LC557142 to LC557151. Accession number of glpQ gene sequence of B. miyamotoi Hetao-1 is LC557152.

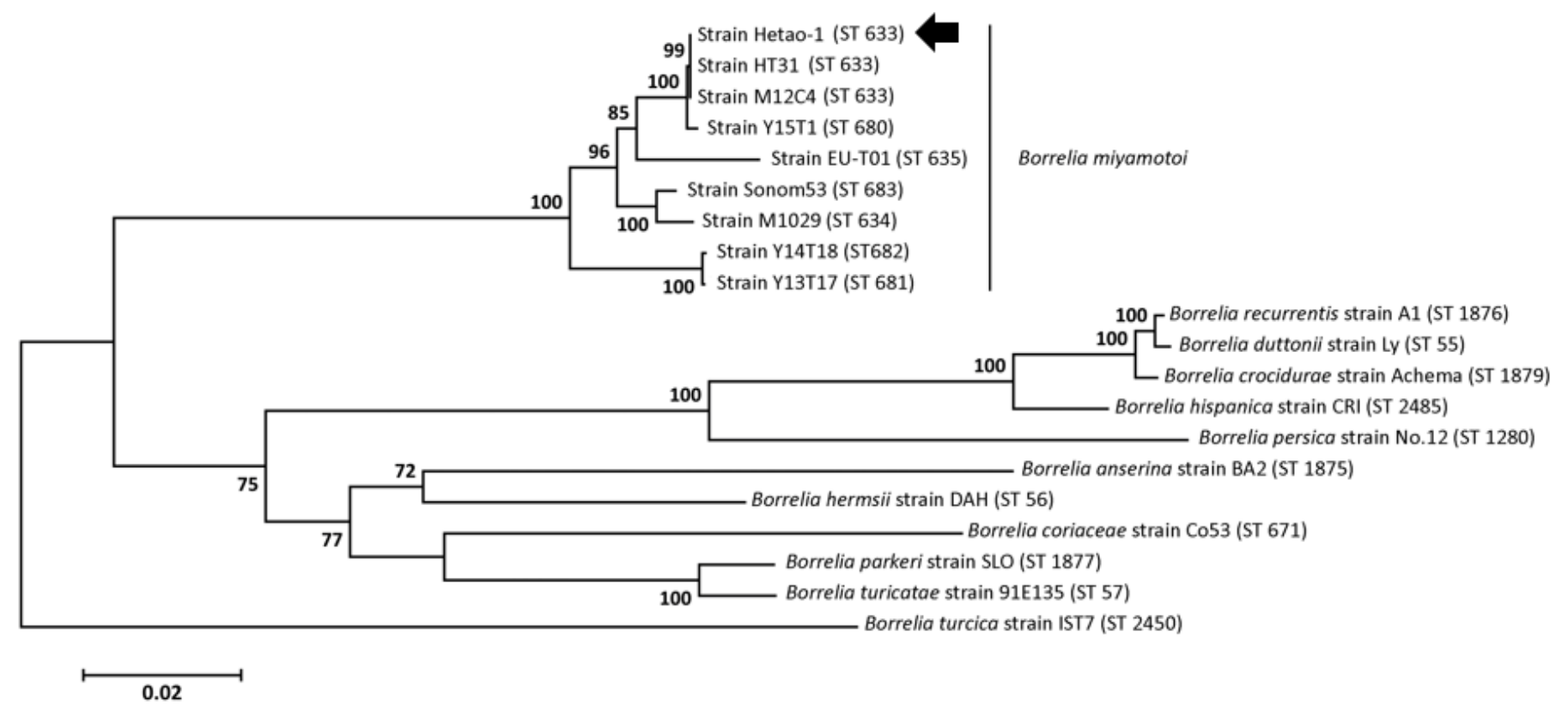




\section{Figure 3}

MLSA analysis of B. miyamotoi Hetao-1 and other Relapsing fever borreliae. A phylogenetic inference of the concatenated housekeeping gene sequences of the representative Relapsing fever borreliae is shown. The arrow indicates the B. miyamotoi strain Hetao-1 isolated in this study. Consensus sequences for the eight housekeeping genes were isolated from the draft genome sequence of B. miyamotoi strains Hetao-1, trimmed to lengths and concatenated in the order: clpA, clpX, nifS, pepX, pyrG, recG, rpIB, and uvrA according to the Borrelia PubMLST database. For phylogenetic reconstruction, the Maximum likelihood model based on the Kimura 2-parameter model with MEGA 6.0 was used with 1000 bootstrap replicates. Borrelia turcica IST7 was used for outgroup. The ST number designated in each strain indicates the "sequence type" number registered in Borrelia PubMLST database.

\section{Supplementary Files}

This is a list of supplementary files associated with this preprint. Click to download.

- GraphicalAbstract.pptx 